\title{
Enhancing Student's Self-Leadership Through a Positive Psychology Intervention? A Randomized Controlled Trial Using an Idiographic Perspective
}

\author{
Udo Konradt $^{1}$ (D) $\cdot$ Stephanie Brombacher ${ }^{1} \cdot$ Yvonne Garbers $^{1} \cdot$ Kai-Philip Otte $^{1}$
}

Accepted: 30 October 2019 / Published online: 30 November 2019

(C) Springer Nature Switzerland AG 2019

\begin{abstract}
Positive psychology interventions have been shown to increase individual well-being and happiness at a nomothetic level. We expand our understanding of their potential impact on individual's self-leadership by adopting an idiographic approach. Moreover, we compare that effect with that of a goal-setting intervention. In a diary study using a randomized controlled design, 60 undergraduates were surveyed daily for 14 consecutive days before an exam and were assigned to one of three conditions: a "three good things" (TGT) intervention in which participants wrote down three positive things they had experienced during the day before going to bed; a "goal-setting" (GS) intervention in which they wrote down three learning goals for the next day; or a placebo control condition. Dynamic modeling of time series revealed that students in the TGT and the GS intervention significantly increased their self-leadership across time at a small to medium effect size. Students in the placebo control group showed no significant change. Contrary to expectations, the TGT intervention was not more strongly associated with self-related strategies, and the GS intervention was not more strongly associated with task-related strategies. This study demonstrates the value of a brief positive psychology intervention, which is comparably effective as a goal-setting intervention in fostering individual self-leadership in academic achievement settings.
\end{abstract}

Keywords Positive psychology $\cdot$ Goal setting $\cdot$ Intervention $\cdot$ Three good things $\cdot$ Selfleadership · Diary study $\cdot$ Time-series analysis

In today's academic institutions and companies, people are facing the importance of and the need for increased empowerment and accountability to be successful (e.g., Ilgen and

Udo Konradt

konradt@psychologie.uni-kiel.de

1 Kiel University, Institute of Psychology, Olshausenstr. 40, 24098 Kiel, Germany 
Pulakos 1999). One psychological approach which can help in providing such autonomy is self-leadership (Manz 1986; Neck and Houghton 2006), described as "a process through which individuals control their own behavior, influencing and leading themselves through the use of specific sets of behavioral and cognitive strategies" (Neck and Houghton 2006, p. 270). Theory assumes that self-leadership increases positive emotional outcomes (Houghton et al. 2012b), and existing research provides support for that self-leadership is associated with higher performance as well with enhanced self-efficacy, better affective responses (Stewart et al. 2011), and greater career success for employees and students (Murphy and Ensher 2001; Raabe et al. 2007).

A promising approach to enhance self-leadership is provided by positive psychology, a branch of psychology concerned with mental well-being that is based on people's strengths (Seligman and Csikszentmihalyi 2000). Positive psychology interventions focus on individuals' overarching emotional and cognitive strengths and competencies by emphasizing positive emotion, engagement, and meaning (Seligman et al. 2005). In the recent past, positive psychology has stimulated both theoretical and applied research to improve individuals' occupational performance and their perceived quality of work (Donaldson et al. 2019; Meyers et al. 2013; Avey et al. 2011).

Despite these developments, less attention has been given to date to fostering individual's cognitive processes, which are for example related to enhanced selfefficacy. More precisely, cognitive processes are also relevant to foster selfleadership whereby individuals navigate, motivate, and lead themselves toward achieving goals.

\section{Self-Leadership: Theoretical Foundations}

Self-leadership refers to a pattern of self-influence to preserve and increase individual effectiveness by "establish[ing] the self-direction and self-motivation needed to perform" (Neck and Manz 1992, p. 682). By adopting theoretical considerations from behavioral reinforcement (Bandura 1977), goal setting (Locke and Latham 2002), intrinsic motivation (Deci 1975), and constructive thought pattern strategies (Ellis 1977; Neck and Manz 1992) self-leadership helps to improve individual self-regulation. Self-leadership consists of (1) behavior-focused, (2) natural reward, and (3) constructive thought strategies (Manz and Neck 2004; Neck and Houghton 2006; Prussia et al. 1998).

Behavior-focused strategies focus on correcting and avoiding inefficient behavior through self-observation, self-goal setting, self-reward, self-correcting feedback, and self-cueing. Self-observation supports self-awareness, thus providing potential to identify and avoid ineffective or unproductive behaviors (Neck and Houghton 2006). Selfgoal setting improves personal performance by providing the self-motivation needed to reduce target-performance discrepancy (Manz 1986; Manz and Neck 2004). Selfreward, self-correcting feedback, and self-cueing also help to direct behavior toward the goal (Stewart et al. 2011). Natural reward strategies focus on finding enjoyment in a task, and can give individuals a greater feeling of competence, interest, and self-control as well as reducing tension (Deci and Ryan 1985). They allow the task itself to be the reward by either focusing attention on existing enjoyable aspects or introducing more 
such aspects into the task (Manz and Neck 2004; Manz and Sims 2001; Neck and Houghton 2006). Finally, constructive thought pattern strategies aim to modify mental processes so that thought patterns become more positive and optimistic, and this then has a significant impact on individual performance (Neck and Houghton 2006). They include self-analysis, improvement of belief systems, positive self-talk, and mental imagery (Manz and Neck 2004).

Empirical research has consistently demonstrated that self-leadership strategies play a decisive role in individual performance. People who score high on selfleadership are found to have higher levels of job performance (Konradt et al. 2009), self-efficacy, and positive affect, and are reported to be more satisfied with their job (Neck 1996; Neck and Manz 1996), to experience less strain (Unsworth and Mason 2012), and to be more creative (Carmeli et al. 2006; Stewart et al. 1996). More recently, Sampl et al. (2017) demonstrated that a self-leadership training specifically developed for academic achievement situations had positive effects on academic self-efficacy and academic performance.

\section{Positive Psychology Interventions and Self-Leadership}

A key aspect of positive psychology is psychological capital, which refers to an individual's positive psychological state of growth and development, including feelings of hope, confidence, optimism, and resilience (Sweetman et al. 2011). The more this psychological capital is activated, the more an individual will be able to make an effort and use techniques to complete tasks; he or she will also be more motivated, will expect better results, and will deal more effectively with obstacles (Luthans et al. 2010). Positive psychology researchers assume that, in addition to these resources, a positive state of mind also creates trust in one's own ability to master change and learn from mistakes, referred to as "opportunity thinking" (Neck and Manz 1992, p. 689; Manz 1992). Consistent with this assumption, Fredrickson (2003) demonstrated that people in a state of positive emotions (i.e., a positive state of mind) show broader thinking (i.e., are concerned not just with solving immediate problems but also with personal growth and development) and a broader set of personal resources in the long run.

To increase psychological capital, several positive psychology interventions (PPIs) have been suggested, such as gratitude exercises (Boehm et al. 2011) or thinking about positive live events (Lyubomirsky et al. 2006) (for meta-analytical overviews see, for example, Sin and Lyubomirsky 2009, or Bolier et al. 2013). Seligman et al. (2005) examined different forms of short PPIs. One of these interventions aimed to increase participants' awareness of what was positive about themselves by instructing them to write down for one week three things that had gone well each day and the reasons for this. In this randomized controlled trial study, the researchers show that participants doing the Three Good Things (TGT) intervention were happier and less depressed when followed up three and six months later (Seligman et al. 2005). Some researchers (Krentzman et al. 2015; Pietrowsky and Mikutta 2012) demonstrated positive effects of the TGT intervention in clinical contexts, and others found similar effects in educational contexts (Chan 2010) and across different age groups (Killen and Macaskill 2015; Proyer et al. 2014; McCabe et al. 2011). 


\section{Goal-Setting Interventions and Self-Leadership}

In addition to PPIs, another path to improve or strengthen self-leadership is provided by goal-setting theory (Locke and Latham 1984). Goal-setting theory is based on Ryan's (1970) hypothesis that conscious goals affect action, with the premise being that people adjust their performance strategies to match what the goal requires. Locke and Latham (2002) defined a goal as "the object or aim of an action, for example, to attain a specific standard of proficiency, usually within a specified time limit." (p. 705). According to goal-setting theory, goals are considered to be a key element in helping individuals to regulate their own behavior, particularly when the goals are specific and challenging but achievable. Recent meta-analytical evidence suggests that goal setting has a robust small to moderate positive effect on behavior change across a wide range of domains and behaviors (Epton et al. 2017). Research on goal setting in occupational settings has demonstrated, for example, that people cope more effectively with personal and social obstacles at their workplace (Bandura 1977, 1991) and develop better task and communication skills (Brown and Latham 2000; Morin and Latham 2000).

Theory and research suggest four mechanisms by which goals affect motivation and performance: (1) choice direction, (2) effort, (3) persistence, and (4) strategies. First, on both a cognitive and a behavioral level, goals direct individuals' attention and effort toward goal-relevant activities and away from those that are goal-irrelevant. Second, ambitious and challenging goals lead to greater effort than less ambitious goals. This has been shown for a broad array of tasks across work and non-work domains (e.g., Bandura and Cervone 1983; Bryan and Locke 1967). Third, high and challenging goals have shown to prolong people's effort (LaPorte and Nath 1976). Fourth, goals affect the use of task-relevant knowledge and strategies (Wood and Locke 1990).

\section{Comparing the Interventions}

Theory suggests that both interventions are expected to increase people's overall selfleadership, although there are certainly differences in how they work. With the positive psychology approach, we expect to target natural reward and constructive thought pattern strategies, which we describe as self-related self-leadership strategies. The participants focus on positive aspects, create more helpful thought patterns, experience more general positive emotions (Seligman et al. 2005), broaden their set of personal resources (broaden-and-build theory, Fredrickson 2003), increase their psychological capital (e.g., confidence, hope, optimism, resilience; Luthans et al. 2004), and become more positive overall. Moreover, natural reward strategies create a sense of optimism about the future, enabling individuals to visualize themselves completing tasks successfully, to focus on their strengths, and to reward themselves for success (Houghton et al. 2012a). Constructive thought pattern strategies also tend to facilitate more positive and optimistic thinking patterns and mental processes that can have a significant impact on individual performance (Neck and Houghton 2006; Neck and Manz 1992, 1996). Strategies of this kind address the whole person; instead of focusing on narrow task-relevant information, they prompt individuals to consider both "what I have" and "who I am" (Luthans et al. 2004), instead of focusing on narrow task-relevant information. 
In contrast to the TGT intervention, we expect the goal-setting (GS) approach to activate primarily behavior-focused strategies, because GS interventions are aimed mainly at triggering cognitive and motivational processes that directly affect selfregulation, such as effort and attention. Indeed, people receiving a GS intervention may feel more rational and focus more on task-related activities, since goal-setting theory indicates that affective processes play only a minor role in goal setting. In addition, people who focus on activities that are directly task-related might be more motivated to accomplish tasks and strive harder to do so, rather than focusing on natural reward strategies or constructive thought patterns, because those strategies focus more on supportive processes within the individual.

Conclusively, we are interested in whether the effects of both interventions on selfleadership differ and whether one intervention can be described as more effective than the other when it comes to increasing self-leadership. Previous research has shown that both interventions can have various outcomes. Moreover, as described above, both interventions could have specific individual effects. However, instead of arguing for one or other intervention, our approach is to explore whether the effects of the two interventions on overall self-leadership are different.

\section{The Idiographic Approach}

Drawing on the distinction between variable and person-centered approaches (Block 1971), we pursue an idiographic approach (also termed person-centered or ipsative). This study is designed to provide more convincing evidence of the causal effects of a TGT and a GS intervention on individual self-leadership. Only one study has examined this question, with non-supportive results (Woodworth et al. 2016). We argue that analyses at the individual level are more adequate than an average nomothetic approach, because psychological theories typically reflect changes within individuals across time. To address this issue, it has been suggested that research should instead focus on individual changes in relevant variables to evaluate PPIs (Eid and Diener 1999; Woodworth et al. 2016). In addition, individual dynamics are likely to differ from interindividual differences, and interindividual analyses can be misleading (Hamaker 2012; Molenaar 2004). Hamaker (2012) argues that there might be substantial variance within each intervention group, and participants might not all profit equally from, or respond equally to, each intervention. Consequently, this might explain the current inconclusive evidence base for the effects of PPIs found in between-subject analyses compared to within-subject analyses (e.g., Seligman et al. 2005; Mongrain and Anselmo-Matthews 2012; Woodworth et al. 2016).

\subsection{Present Study}

Our study represents a first attempt to examine the effects of a PPI on individual selfleadership. By so doing, our study seeks to fill three critical gaps in the literature. First, trainings to foster self-regulation behavior (i.e., self-leadership) have often used very comprehensive approaches (e.g., durations of several months and hours per training session, see Dignath et al. 2008; and Sitzmann and Ely 2011, for meta-analytic overviews), but this is comparatively expensive and difficult to achieve in both 
managerial and academic settings. Moreover, meta-analytical evidence (see above) also found first evidence for more positive effects of shorter trainings. Therefore, our study examines whether self-leadership can be improved effectively within a short time period of two weeks. Second, existing research typically provides results on the effectiveness of a PPI but fails to give an answer how this effect relates to other established forms of interventions such as GS interventions. This is necessary - and not comparable with the implementation of a placebo control group - to differentiate between the mere effect of an intervention and the effectiveness or efficiency. It is imperative for teachers and managers to know to what extent different interventions differ in their effects because of limited time and budget. The effectiveness of GS interventions has been demonstrated across various contexts (Asmus et al. 2015; Mento et al. 1987), in relation to both well-being (MacLeod et al. 2008) and self-leadership (Neck et al. 2004; Godwin et al. 1999). By comparing two interventions we intend to investigate whether a PPI is beneficial in terms of supporting self-leadership, and also how favorable this form of intervention is.

Third, theories of self-regulation (Bandura 1991), positive psychology (Fredrickson 1998, 2003; Seligman and Csikszentmihalyi 2000) and selfleadership (Manz 1986; Houghton et al. 2012a, b; Neck and Houghton 2006) describe psychological processes that take place within people across time and are thus idiographic in nature. Surprisingly, very little research has taken account of this fact, since almost all studies of PPIs are based on nomothetic approaches (for a notable exception, see Woodworth et al. 2016). However, Molenaar (2004) and Hamaker (2012) argue that studies using nomothetic approaches are not informative with regard to individual change over time. The proposition that results from the population are generalized to the individual is only appropriate when conditions of ergodicity are met, that is that processes are homogeneous across individuals and stationary over time, conditions, which are unlikely to be the case for psychological processes (for details, see Hamaker 2012). Consequently, we close this gap by using an idiographic approach (Bolger and Laurenceau 2013) in the present study. In the present study, we thus delineate these different temporal patterns by means of time-series analysis, which allow us to derive more biased-free effects.

According to these gaps, we deduce the following hypotheses and research question. We expect that increasing psychological capital will also result in increased selfleadership (cf. Luthans et al. 2010) because it will enable individuals to focus on enjoyable elements of the task (i.e., positive things) (Manz and Neck 2004; Neck and Houghton 2006) and will facilitate more positive and optimistic thinking patterns and mental processes (Neck and Houghton 2006; Neck and Manz 1992, 1996). Consequently, goal setting is a key variable for behavior-focused strategies in self-leadership, because it directly influences self-reward, self-correcting feedback, and self-cueing, all of which help to determine supportive behavior in relation to the goal. Taken together, these findings suggest the following hypothesis:

Hypothesis 1a: People that receive a TGT intervention will increase their overall individual self-leadership.

Hypothesis 1b: People that receive a GS intervention will increase their overall individual self-leadership. 
We also anticipate that the TGT intervention will primarily activate more self-related aspects of self-leadership.

Hypothesis 2a: A TGT intervention has a more positive effect on self-related selfleadership than a GS intervention.

Hypothesis 2b: A GS intervention has a more positive effect on task-related selfleadership than a TGT intervention.

As theory and research didn't provide unambiguous arguments in favor of one intervention, we seek to explore whether the two interventions have different effects on overall self-leadership.

Research Question: Is one of the two interventions more effective than the other when it comes to increasing self-leadership?

\section{Method}

\subsection{Participants and Design}

Seventy-two undergraduate students at a large German university who were preparing for an upcoming written exam were invited to participate in this study and $N=60$ gave their consent. They constitute a convenience sample consisting of more woman $(n=55)$ than men $(n=5)$ and mean age of 21.95 years $(S D=4.01)$. All people were included in the data collection. The whole dataset contained a total of 840 observations (i.e., 60 subjects $\times 14$ points in time). The study was based on a within-subjects factorial design (TGT vs. GS vs. control). Students participated either for course credits or for monetary compensation and were randomly assigned to one of the three conditions.

\subsection{Procedure}

One month before the exam undergraduates were asked to participate in a study of self-regulation. A student assistant who had been trained delivered information material and answered simple questions about it. Participants who agreed to participate in the study were randomly allocated by using a computer-generated random number list to randomize the participants into one of three groups and received written instructions on the nature of the task. They were also given an envelope, which contained a cover letter explaining the purpose of the study, the pre-test questionnaire, the fourteen daily questionnaires and the last day's additional questionnaire. Also, the participants had to indicate the date of their exam. Fourteen days before their exam participants received an e-mail, reminding them of the beginning of the study. They were told that the study involved a daily task and a questionnaire, and that they would need to provide data every day for two weeks, filling in the questionnaire after they had completed their study for that day. Those who did not return their diaries were contacted via e-mail and reminded to return study material. 


\subsection{Interventions}

Participants in the intervention conditions had to fulfill a daily task on all fourteen consecutive days of the study. The instruction was "The study will run over a two-week period - the two weeks before your exam. During these two weeks you will do a small exercise every evening and then complete a short questionnaire. The daily task will only take a few minutes to complete so that you are not too busy during the exam preparation." In the TGT condition $(n=18)$, the task was to write down three positive things that happened during the day. The present study used a slightly modified version of the TGT intervention of Seligman et al. (2005). In the goal-setting condition $(n=20)$ participants were instructed to write down three learning goals for the next day (based on Grant and Dweck 2003; Miller et al. 1993; Seijts and Latham 2005). Corresponding to the procedure chosen by Seear and Vella-Brodrick (2013), participants were asked to write down three things that had gone well that day, without giving any causal explanations. In line with Emmons and McCullough (2003), participants in the control condition $(n=22)$ were asked to write down one positive, one negative, and one neutral thing they had experienced during the day. This task provides an appropriate degree of comparability between the two interventions but still permits enough delimitation with regard to content. The three groups neither differed in age $(F(2,59)=0.52, n s$. ), gender $(F(2,59)=0.65, n s$.$) , nor in previous self-leadership (F(2,59)=0.62, n s$.$) .$

\subsection{Measures}

Self-leadership Self-leadership was measured with the nine-item Abbreviated SelfLeadership Questionnaire (ASLQ) from Houghton et al. (2012a), using a five-point Likert scale from 1 (strongly disagree) to 5 (strongly agree). The ALSQ is a shortened version of the Revised Self-Leadership Questionnaire (RSLQ, Houghton and Neck 2002) and comprises nine items measuring three factors of behavior awareness and volition, task motivation, and constructive cognition. In accordance with the RSLQ behavior awareness and volition items were taken as indicators for task-related selfleadership and the constructive cognition items as indicators for self-related selfleadership. A sample item for constructive thought pattern strategies was "Sometimes I talk to myself (out loud or in my head) to work through difficult situations". The results from this questionnaire showed acceptable levels of reliability: Cronbach's alpha ranged from .80 to .87 across the fourteen waves.

Self-related self-leadership Three items ("I establish specific goals for my own performance", "I make a point to keep track of how well I'm doing at work"," I work toward specific goals I have set for myself') from the ASLQ were used to measure self-related self-leadership, and showed acceptable reliability (range: $\alpha=.68$ to .80 across the waves).

Task-related self-leadership Three items from the ASLQ ("Sometimes I talk to myself (out loud or in my head) to cope with difficult situations"," I try to mentally evaluate the accuracy of my own beliefs about situations I am having problems with", " I think about my own beliefs and assumptions whenever I encounter a difficult situation") from the ASLQ constituted task-related self-leadership, with acceptable reliability (range: $\alpha=.70$ to .89 across the waves). 
Demographics Participants provided data on their gender, age, and the term that they were enrolled in during the study in the pre-test questionnaire. As the inclusion of these variables had little to no influence on the estimates, we omitted them from the final models.

\subsection{Data Analyses}

In this study we used a time series model to examine our hypotheses (for introductions and applications in psychological research, see for example Hamaker et al. 2018; Jebb and Tay 2017). Time series analysis allows for the identification of within-subject changes across different time periods and for identifying the relationships among variables when large longitudinal data are gathered on single subjects or units, which is here the case. Given the nested longitudinal data structure (days nested within persons), we performed a two-level time-series analysis with a univariate first-order autoregressive $\mathrm{AR}(1)$ model for a continuous dependent variable with a random intercept, random AR(1) slope, random slope, and random self-leadership variance. According to Scheines et al. (1999), point estimates (e.g., the expected a-posteriori mean or median) for each parameter were calculated. To assess the uncertainty about the point estimates, we used the posteriori standard deviation and the $95 \%$ central credibility interval. We used random autoregressive and structural parameters to allow for inter-individual differences. Consequently, all individuals are assumed to have different means, autoregressive coefficients, and residual variances. Asparouhov et al. (2018) recommend using models with random variances and covariances as long as the Markov Chain Monte Carlo converges since "nonrandom parameters gives us the ability to combine data across the population to obtain more accurate time-series and structural parameters" (p. 382). Also, as shown by Jongerling et al. (2015), modeling the variance as fixed across individuals, when it should be modeled as a random effect, leads to biased parameter estimates. Our models were estimated with dynamic structural equation modeling (DSEM) using a Bayesian estimator in Mplus 8.0, using 20,000 iterations and two Markov chains as recommended for Bayesian structural equation modeling (Asparouhov et al. 2015). DSEM is a new statistical framework for studying observed and latent variables in structural equation models and is suitable for analyzing longitudinal data where observations from multiple individuals, which are particularly collected at many points in time (for details, see Asparouhov et al. 2018).

The Deviance Information Criterion (DIC; Spiegelhalter et al. 2002), which is a Bayesian generalization of the fit indices AIC and BIC in maximum likelihood, was used for comparing models, with low values indicating a better model fit. Since DIC precision is difficult to achieve when many parameters have to be integrated through the Markov chain Monte Carlo iterations, we verified the precision of the DIC estimate by comparing parameters across runs using different random seeds for the same model (cf., Asparouhov et al. 2018). In addition, a Potential Scale Reduction (PSR) criterion (Gelman and Rubin 1992) was checked, with a value close to 1 indicates that the between-chain variation is small relative to the within-chain variation and is considered to provide strong evidence of convergence. Finally, trace plots were checked for an absence of trends, spikes, or other irregularities. With all our models, we found there were only negligible irregularities or no irregularities at all. $95 \%$ credibility intervals excluding zero indicate statistically significant relationships. 


\subsection{Preliminary Analyses}

Prior to hypotheses testing, we conducted a series of analyses to determine whether there were any spurious effects due to group differences in baseline characteristics, attrition and missing data, compliance, discriminant validity of our measures, and power issues. Analysis of variance and chi-squares showed no differences between the treatment and control groups on any of the demographic characteristics. None of the participants dropped out. The response rates were high and varied between 94 and $100 \%$. To minimize the bias associated with this occasional attrition, obviously missing completely at random (Little-MCAR-Test $\chi^{2}=0.52, \mathrm{df}=2, n s$.), we used expectation maximization algorithms to impute missing data.

Since one of the major challenges in intervention and diary studies is to maintain participant attendance and compliance (Dumas et al. 2001), it is essential to ensure that there is 'intervention fidelity', defined as implementing the experimental manipulation as originally intended and treating all participants in a similar manner. Thus, participants were asked on the last day how often they had omitted to follow all of the daily requirements. Results indicated that $59.3 \%$ of the participants fully complied with the prescribed exercises and only 10 participants had failed to complete the exercises on a maximum of three out of fourteen days. The mean non-attendance rate was 1.05 days $(S D=1.49)$ and was distributed equally between the three groups $(1.09, S D=1.73$, for TGT; $1.71, S D=1.51$, for GS; and $0.85, S D=1.78$, for the controls; $F=1.50, d f=2$, $n s)$. Thus, intervention fidelity was considered as fulfilled.

As a preliminary step, we conducted a Multilevel Confirmatory Factor Analysis (MCFA) over the fourteen daily items of the overall nested self-leadership scale scores to provide evidence for our hypothesized factor structure. Compared to a set of confirmatory factor analyses, a MCFA was used to extend the power and to minimize the risk to estimate incorrect parameters in non-independent observations (du Toit and $\mathrm{du}$ Toit 2008). Results of the MCFA showed that the abbreviated self-leadership questionnaire had reasonable fit, RMSEA $=.051, \mathrm{CFI}=.921, \mathrm{SRMR}$ within $=.054$, SRMRbetween $=.151$, also indicating that the factor loading of each item on the latent factor is the same across days (i.e., metric invariance). In addition, to assess the factorial validity of daily measures, a MCFA for the hypothesized two-factor model with the task- and self-related items (Hypotheses 2a-b) revealed an excellent fit (RMSEA = $\left..025, \mathrm{CFI}=.992, \mathrm{SRMR}_{\text {within }}=.019, \mathrm{SRMR}_{\text {between }}=.041\right)$ and a comparatively better fit than a single-factor model, thus indicating discriminant validity.

\section{Results}

Means, standard deviations, reliabilities, and between-subject correlations among all the study variables are presented in Table 1. Within-subject correlations are also presented (above the diagonal). Interestingly, the averaged between-subject measures of the three self-leadership constructs were very highly positively correlated but were moderately positively correlated within subjects. This may reflect valid individual differences in the between-subject variance such that subjects show considerable variability in self-leadership over time, a fact which could not have been captured by averaged between-subject scores. Finally, the correlation pattern at the within-subject 
Table 1 Descriptive statistics, internal consistency reliabilities, and correlations

\begin{tabular}{|c|c|c|c|c|c|c|c|c|c|c|c|}
\hline & Variable & Mean $(S D)$ & 1 & 2 & 3 & 4 & 5 & 6 & 7 & 8 & 9 \\
\hline 1. & $\begin{array}{l}\text { TGT vs. GS } \\
\text { Intervention }\end{array}$ & - & $\mathrm{n} / \mathrm{a}$ & & & & & & & & \\
\hline 2. & TGT vs. Control & - & $-\mathrm{a}$ & $\mathrm{n} / \mathrm{a}$ & & & & & & & \\
\hline 3. & GS vs. Control & - & $\_^{\mathrm{a}}$ & $-\mathrm{a}$ & $\mathrm{n} / \mathrm{a}$ & & & & & & \\
\hline 4. & Self-leadership (SL) & $3.75(0.21)$ & -.05 & .12 & .18 & .84 & $.33 * * *$ & $.26 * * *$ & & & \\
\hline 5. & Self-related SL & $3.74(0.19)$ & -.04 & .15 & .20 & $.78 * * *$ & .75 & $.66^{* * * *}$ & & & \\
\hline 6. & Task-related SL & $3.79(0.20)$ & -.05 & .11 & .18 & $.69 * * *$ & $.89 * * *$ & .79 & & & \\
\hline 7. & Age & $21.94(16.08)$ & -.14 & .00 & .13 & .21 & $.22 *$ & $.23 *$ & $\mathrm{n} / \mathrm{a}$ & & \\
\hline 8. & Gender $^{\mathrm{b}}$ & - & $-.25^{*}$ & -.19 & -.20 & $-.23 *$ & $-.24 *$ & $-.28 *$ & -.05 & $\mathrm{n} / \mathrm{a}$ & \\
\hline 9. & Term & $1.78(1.52)$ & .11 & .13 & -.23 & .04 & .05 & .04 & -.15 & -.15 & $\mathrm{n} / \mathrm{a}$ \\
\hline
\end{tabular}

Lower half of the table depicts between-subject correlations $(N=60)$. Upper half depicts within-subject correlations $(N=840)$. Reliabilities are mentioned in the diagonal of the table where appropriate

Note. TGT three good things, GS goal setting, $n / a$ not applicable

$* p<.05 ; * * p<.01 ; * * * p<.001$

${ }^{a}$ Because the study utilized a completely crossed design, correlations among independent variables are zero by definition and therefore are not shown

b $1=$ female, 2 = male

level demonstrates evidence of both convergent and discriminant validity, as all three constructs are positively correlated, but still provide substantial distinct information.

Hypotheses 1a and 1b, which stated that the TGT and the GS intervention each have a positive direct effect on self-leadership, were supported (see Table 2). The average standardized effects of treatments on slope (changes) in self-leadership across time was 0.331 (CI [0.223, 0.442]) in the TGT group, 0.201 (CI [0.089, 0.301]) in the GS group, and 0.143 (CI $[-0.001,0.274])$ in the control group. Since $95 \%$ credibility intervals for both intervention groups do not include zero, these effects differ from zero. Only the CI in the control group contained zero, indicating that there is no evidence of a significant effect on self-leadership over time in this group. These effects are corresponding to an increase of $13.2 \%$ and $8.0 \%$ in self-leadership among of people in the TGT group and

Table 2 Point estimates (posterior means), 95\% credible intervals, and posterior standard deviations for random intercept, autoregressive, and slope effects in the three groups

\begin{tabular}{|c|c|c|c|c|c|c|}
\hline \multirow[t]{3}{*}{ Parameter } & \multicolumn{6}{|l|}{ Treatment } \\
\hline & \multicolumn{2}{|c|}{ Three good things $(n=18)$} & \multicolumn{2}{|l|}{ Goal setting $(n=20)$} & \multicolumn{2}{|l|}{ Control $(n=22)$} \\
\hline & Estimate $[95 \% \mathrm{CI}]$ & $P S D$ & Estimate $[95 \% \mathrm{CI}]$ & $P S D$ & Estimate $[95 \% \mathrm{CI}]$ & $P S D$ \\
\hline Intercept & $0.569[0.496,0.645]$ & 0.038 & $0.561[0.481,0.635]$ & 0.039 & $0.745[0.658,0.829]$ & 0.043 \\
\hline Autoregression & $0.302[0.189,0.375]$ & 0.045 & $0.360[0.281,0.420]$ & 0.036 & $0.184[0.084,0.339]$ & 0.072 \\
\hline Slope & $0.331[0.223,0.442]$ & 0.043 & $0.201[0.089,0.301]$ & 0.041 & $0.143[-0.001,0.274]$ & 0.054 \\
\hline
\end{tabular}

Note. CI credibility interval, PSD posterior standard deviation 
GS group, respectively. Regarding the effect size, i.e. magnitude of intervention impact, the intervention increases the probability of enhancing individual self-leadership at a medium level from 0.223 to 0.442 for the TGT group, and at a low to medium level from 0.089 to 0.301 for the GS group.

Hypothesis $2 \mathrm{a}$, which predicted that the positive effect on self-related self-leadership for people receiving a TGT intervention is higher than for those receiving a GS intervention, was rejected. People in the TGT group did not significantly increase their self-related self-leadership across time (slope $=0.049, P S D=0.050$, CI $[-0.045$, $0.147]$ ), nor did those in the GS group (slope $=0.040, P S D=0.055$, CI $[-0.077$, $0.145]$ ). Hypothesis $2 \mathrm{~b}$, which predicted that the positive effect for people receiving a GS intervention on task-related self-leadership is higher than for those receiving a TGT intervention, was also rejected. Although people in the GS group showed a significantly increase in their task-related self-leadership (slope $=0.100, P S D=0.047$, CI $[0.009$, $0.195]$ ) compared to no increase in the TGT group (slope $=0.042, P S D=0.054, \mathrm{CI}$ $[-0.152,0.062]$ ), these differences were non-significant (point estimate of differences = $0.051, P S D=0.120$, CI $[-0.185,0.282])$. Finally, the research question sought to determine whether one of the two interventions is more effective than the other when it comes to increasing self-leadership. However, although the slope of the TGT intervention was greater than the slope of the GS intervention, the credibility intervals of both estimates overlapped, indicating no statistically significant difference (TGT intervention: 0.331, CI [0.223, 0.442]); GS intervention: 0.201 (CI [0.089, 0.301]).

\section{Discussion}

The purpose of this study was to explore the absolute and relative effects of a TGT intervention and a GS intervention on student's self-leadership within a short time period of two weeks. We found that the TGT intervention significantly increased the self-regulatory processes of overall self-leadership, as did the GS intervention. However, the TGT intervention showed stronger positive effects than the GS variant. Benchmarking the estimates according to the field of organizational behavior and human resources (Bosco et al. 2015), we found small to medium effects. Since these self-regulatory processes have been shown to be positively associated with motivation, behavior, and performance (e.g., Stewart et al. 2011), we therefore anticipate that the intervention should also show significant beneficial behavioral effects (e.g., Hauschildt and Konradt 2012). The current study extends previous lines of research on the effects of PPIs to provoke experiences and feelings in three meaningful ways. First, we established that PPI had an effect on cognitive processes involved in self-regulation and self-leadership. This is an important finding because self-leadership has been shown to have positive effects across a broad range of outcomes, including selfreferential processes, motivation, strain, and performance (Andressen et al. 2012; Murphy and Ensher 2001; Raabe et al. 2007; Stewart et al. 2011; Unsworth and Mason 2012). In addition to this finding, the results of our study also demonstrated that the size of the PPI effect on self-leadership corresponds to the size of the GS effect. Thus, this study adds to prior studies that focused almost exclusively on affective effects of PPI or did not compare the strength of effects of different interventions. The estimate that we obtained for the PPI in our study falls within the meta-analysis 
confidence interval of estimates found for the effects of GS interventions (Epton et al. 2017) and underlines the effectiveness of positive psychology interventions.

Second, we found no differential effects for either type of intervention with regard to self- and task-specific self-leadership processes. We can speculate that the specific effects of a brief exercise, covering a relatively short time span of 14 days, may not fully unfold over that period. Like most other psychological theories, self-leadership theory is not "time-scale complete" (Arrow et al. 2004) in that it does not specify a time scale for its variables, relationships, and boundary conditions. Consequently, we cannot make theory-driven choices regarding when and how often processes should be observed or make valid predictions about the time span in which effects should unfold (Arrow et al. 2004). To substantiate the finding, it is thus important to replicate this interval-contingent study using varying time intervals for the participants' self-reporting.

Third, the results of this study should be interpreted in light of the methodologically rigorous evaluation of the effectiveness of a PPI, including a study with a randomized controlled trial that allowed us to derive valid estimates and draw convincing conclusions (for a meta-analysis, see Donaldson et al. 2019). However, a single study is inherently limited to its target population and the number of interventions and outcomes, which potentially limit generalizability. It should also be noted that this study is also the first to apply statistical time-series analysis to PPI, which has several benefits. At a substantive level, it allowed us to examine the effects of PPI at the idiographic level, which is more consistent with associated theories that assume individual rather than average overall effects (e.g., Fredrickson 1998, 2003; Seligman and Csikszentmihalyi 2000). At a methodological level, this approach enabled us to delineate the different temporal patterns, such as for autoregressive and true effects (Schmid and Duan 2014). Consequently, the estimates obtained in this study are neither attenuated by measurement error, nor overestimated by autocorrelations of which we could show that they were substantial. For this reason, our results represent conservative estimates of the true effects.

\subsection{Limitations and Future Research}

Despite our randomized controlled trial study design, rigorous statistical analyses, and encouraging findings, this study has some limitations that restrict the findings, and these could be addressed by future research. A first limitation of the research is the limited time frame for the observation and the measures we used. Although it was one of the aims of this study to show that both interventions produce short-term effects, brief observation intervals might make people more prone to overestimate their selfleadership immediately after the intervention, and their level of self-leadership might subsequently decline. Longer observation intervals of more than one month follow-ups (e.g., Maykrantz and Houghton 2018; Sampl et al. 2017) would provide a more conservative test of whether the effects of the intervention are sustained. Also, even though diary studies represent an established method of exploring within-person psychological processes, they are nevertheless retrospective in nature and thus susceptible to retrospective memory and self-report bias. Extensions and recent innovations of diary studies and experience sampling methods - which have their own weaknesses could provide a more valid assessment of any intervention effects (see Beal 2015). In addition, by using a short measure of self-leadership, we potentially have restricted the 
content validity. Houghton et al. (2012a) recommend that these abbreviated sub-scales should not be used in isolation to measure specific categories of self-leadership strategies, but rather as an overall self-leadership construct. Although we found coherent and rationale groupings of self- and task-related self-leadership strategies, this presents a possible limitation to the study, which could have affected the results.

A second limitation of this study is that further work is needed to understand the causal pathways by which the PPI is linked to self-leadership. State optimism and event hope - which refers to an individual's goal-oriented expectations that include both agency thinking (i.e., a person's perceived capability to initiate and sustain actions to achieve goals) and pathway thinking (i.e., a person's capacity to find ways to help meet goals) - might act as possible mediators (Luthans et al. 2004). Evidence suggests that optimism and effective coping style are positively related to individual self-leadership (Dolbier et al. 2001; Maykrantz and Houghton 2018).

A third limitation pertains to the uniqueness of the student sample, which does not reflect the diversity and range of individuals and may limit the generalizability of our findings to other academic and non-academic settings. Although meta-analysis of student samples provided evidence that student samples are not substantially different from non-student samples (Wheeler et al. 2014), they may lead to smaller effect sizes of observed statistical relationships. Employed adults, for instance, may differ from student populations in many ways, including the repertoire of alternative cognitive and behavioral strategies in order to cope with requirements, which may attenuate the effects found in this study.

Finally, another open question is whether the effects found in this study of people who are facing a stressful life event (i.e., an exam), where engaging in self-leadership is particularly helpful in enabling them to cope with stress and strain (Houghton et al. 2012b; Maykrantz and Houghton 2018; Unsworth and Mason 2012), may generalize to less stressful everyday situations. Hence, future research should establish the external validity of our proposed relationships in diverse settings.

\section{Conclusion}

This study adds to the body of research on positive interventions by first demonstrating that a short TGT intervention has a positive within-subjects effect on self-leadership. The findings indicate that this intervention led to a small positive increase in self-leadership of about the same size as that produced by a GS intervention. Also, both interventions were found to trigger overall self-leadership, rather than specific self- or task-related subcomponents of self-leadership. The study adds to the growing literature that shows the potential value of positive psychology as a short-time intervention for self-regulation in academic achievement settings and as a supplement to traditional interventions.

Acknowledgments We gratefully acknowledge the support of our students who participated in many kinds to prepare and make possible this study.

Funding There is no funding source. Ethical approval: This article does not contain any studies with human participants or animals performed by any of the authors. Informed consent: Informed consent was obtained from all individual participants included in the study. 


\section{Compliance with Ethical Standards}

Conflict of Interest The authors declare that they have no conflict of interest.

\section{References}

Andressen, P., Konradt, U., \& Neck, C. P. (2012). The relation between self-leadership and transformational leadership: Competing models and the moderating role of virtuality. Journal of Leadership \& Organizational Studies, 19, 68-82. https://doi.org/10.1177/1548051811425047.

Arrow, H., Poole, M. S., Henry, K. B., Wheelan, S., \& Mooreland, R. L. (2004). Time, change, and development: The temporal perspective on groups. Small Group Research, 35, 73-105. https://doi. org/10.1177/1046496403259757.

Asmus, S., Karl, F., Mohnen, A., \& Reinhart, G. (2015). The impact of goal-setting on worker performanceempirical evidence from a real-effort production experiment. Procedia CIRP, 26, 127-132. https://doi. org/10.1016/j.procir.2015.02.086.

Asparouhov, T., Muthén, B., \& Morin, A. J. (2015). Bayesian structural equation modeling with crossloadings and residual covariances: Comments on Stromeyer et al. Journal of Management, 41, 15611577. https://doi.org/10.1177/0149206315591075.

Asparouhov, T., Hamaker, E. L., \& Muthén, B. (2018). Dynamic structural equation models. Structural Equation Modeling: A Multidisciplinary Journal, 25, 359-388. https://doi.org/10.1080 /10705511.2017.1406803.

Avey, J. B., Reichard, R. J., Luthans, F., \& Mhatre, K. H. (2011). Meta-analysis of the impact of positive psychological capital on employee attitudes, behaviors, and performance. Human Resource Development Quarterly, 22, 127-152. https://doi.org/10.1002/hrdq.20070.

Bandura, A. (1977). Self-efficacy: Toward a unifying theory of behavioral change. Psychological Review, 84, 191-215. https://doi.org/10.1037//0033-295x.84.2.191.

Bandura, A. (1991). Social cognitive theory of self-regulation. Organizational Behavior and Human Decision Processes, 50, 248-287. https://doi.org/10.1016/0749-5978(91)90022-1.

Bandura, A., \& Cervone, D. (1983). Self-evaluative and self-efficacy mechanisms governing the motivational effects of goal systems. Journal of Personality and Social Psychology, 45, 1017-1028. https://doi. org/10.1037//0022-3514.45.5.1017.

Beal, D. J. (2015). ESM 2.0: State of the art and future potential of experience sampling methods in organizational research. Annual Review of Organizational Psychology and Organizational Behavior, 2, 383-407. https://doi.org/10.1146/annurev-orgpsych-032414-111335.

Block, J. (1971). Lives through time. Berkeley, CA: Bancroft Books.

Boehm, J. K., Lyubomirsky, S., \& Sheldon, K. M. (2011). A longitudinal experimental study comparing the effectiveness of happiness-enhancing strategies in Anglo Americans and Asian Americans. Cognition \& Emotion, 25, 1263-1272. https://doi.org/10.1080/02699931.2010.541227.

Bolger, N., \& Laurenceau, J. P. (2013). Intensive longitudinal methods: An introduction to diary and experience sampling research. New York, NY: Guilford. https://doi.org/10.1177/1049731513495458.

Bolier, L., Haverman, M., Westerhof, G. J., Riper, H., Smit, F., \& Bohlmeijer, E. (2013). Positive psychology interventions: A meta-analysis of randomized controlled studies. BMC Public Health, 13, 119. https://doi. org/10.1186/1471-2458-13-119.

Bosco, F. A., Aguinis, H., Singh, K., Field, J. G., \& Pierce, C. A. (2015). Correlational effect size benchmarks. Journal of Applied Psychology, 100, 431-449. https://doi.org/10.1037/a0038047.

Brown, T., \& Latham, G. (2000). The effects of goal setting and self-instruction training on the performance of unionized employees. Industrial Relations, 55, 80-95. https://doi.org/10.7202/051292ar.

Bryan, J. F., \& Locke, E. A. (1967). Goal setting as the specification of purpose. In P. W. Conway (Ed.), Development of volitional competence. Selected readings (pp. 184-189). New York, NY: MSS Information Corporation.

Carmeli, A., Meitar, R., \& Weisberg, J. (2006). Self-leadership skills and innovative behavior at work. International Journal of Manpower, 27, 75-90. https://doi.org/10.1108/01437720610652853.

Chan, D. W. (2010). Gratitude, gratitude intervention and subjective well-being among Chinese school teachers in Hong Kong. Educational Psychology, 30, 139-153. https://doi.org/10.1080 /01443410903493934.

Deci, E. L. (1975). Intrinsic motivation. New York, NY: Plenum. https://doi.org/10.1007/978-1-4613-4446-9_3. 
Deci, E. L., \& Ryan, R. (1985). The support of autonomy and control of behavior. Journal of Personality and Social Psychology, 53, 1024-1037. https://doi.org/10.1037//0022-3514.53.6.102.

Dignath, C., Büttner, G., \& Langfeldt, H. P. (2008). How can primary school students learn self-regulated learning strategies most effectively? A meta-analysis on self-regulation training programmes. Educational Research Review, 3, 101-129.

Dolbier, C. L., Soderstrom, M., \& Steinhardt, M. A. (2001). The relationships between self-leadership and enhanced psychological, health, and work outcomes. The Journal of Psychology: Interdisciplinary and Applied, 135, 469-485. https://doi.org/10.1080/00223980109603713.

Donaldson, S. I., Lee, J. Y., \& Donaldson, S. I. (2019). Evaluating positive psychology interventions at work: A systematic review and meta-analysis. International Journal of Applied Positive Psychology. Advance online publication. https://doi.org/10.1007/s41042-019-00021-8.

du Toit, S. H., \& du Toit, M. (2008). Multilevel structural equation modeling. In J. de Leeuw \& E. Meijer (Eds.), Handbook of multilevel analysis (pp. 435-478). New York, NY: Springer.

Dumas, J. E., Lynch, A. M., Laughlin, J. E., Philips Smith, E., \& Prinz, R. J. (2001). Promoting intervention fidelity: Conceptual issues, methods, and preliminary results from the EARLY ALLIANCE prevention trial. American Journal of Preventive Medicine, 20, 38-47. https://doi.org/10.1016/s0749-3797(00 00272-5.

Eid, M., \& Diener, E. (1999). Intraindividual variability in affect: Reliability, validity, and personality correlates. Journal of Personality and Social Psychology, 76, 662-676. https://doi.org/10.1037//00223514.76.4.662.

Ellis, A. (1977). The basic clinical theory of rational-emotive therapy. New York, NY: Springer.

Emmons, R. A., \& McCullough, M. E. (2003). Counting blessings versus burdens: An experimental investigation of gratitude and subjective well-being in daily life. Journal of Personality and Social Psychology, 84, 377-389. https://doi.org/10.1037//0022-3514.84.2.377.

Epton, T., Currie, S., \& Armitage, C. J. (2017). Unique effects of setting goals on behavior change: Systematic review and meta-analysis. Journal of Consulting and Clinical Psychology, 85, 1182-1198 https://doi. org/10.1037/ccp0000260.

Fredrickson, B. (1998). What good are positive emotions? Review of General Psychology, 2, 300-319. https://doi.org/10.1037//1089-2680.2.3.300.

Fredrickson, B. (2003). The value of positive emotions. American Scientist, 91, 330-335. https://doi. org/10.1511/2003.26.865.

Gelman, A., \& Rubin, D. B. (1992). Inference from iterative simulation using multiple sequences. Statistical Science, 457-472. https://doi.org/10.1214/ss/1177011136.

Godwin, J. L., Neck, C. P., \& Houghton, J. D. (1999). The impact of thought self-leadership on individual goal performance: A cognitive perspective. Journal of Management Development, 18, 153-170. https://doi. org/10.1108/02621719910257738.

Grant, H., \& Dweck, C. S. (2003). Clarifying achievement goals and their impact. Journal of Personality and Social Psychology, 85, 541-553. https://doi.org/10.1037/0022-3514.85.3.541.

Hamaker, E. (2012). Why researchers should think "within-person": A paradigmatic rationale. In M. R. Mehl \& T. S. Conner (Eds.), Handbook of research methods for studying daily life (pp. 43-61). New York, NY: Guilford Press. https://doi.org/10.1007/s10608-006-9074-1.

Hamaker, E. L., Asparouhov, T., Brose, A., Schmiedek, F., \& Muthén, B. (2018). At the frontiers of modeling intensive longitudinal data: Dynamic structural equation models for the affective measurements from the COGITO study. Multivariate Behavioral Research. Advance online publication. Multivariate Behavioral Research. https://doi.org/10.1080/00273171.2018.1446819.

Hauschildt, K., \& Konradt, U. (2012). The effect of self-leadership on individual's job performance in teams. Leadership, 8, 145-168. https://doi.org/10.1177/1742715011429588.

Houghton, J. D., \& Neck, C. P. (2002). The revised self-leadership questionnaire: Testing a hierarchical factor structure for self-leadership. Journal of Managerial Psychology, 17, 672-691. https://doi.org/10.1108 /02683940210450484.

Houghton, J. D., Dawley, D., \& DiLiello, T. C. (2012a). The abbreviated self-leadership questionnaire (ASLQ): A more concise measure of self-leadership. International Journal of Leadership Studies, 7, 217-232. https://doi.org/10.1049/et.2009.0618.

Houghton, J. D., Wu, J., Godwin, J. L., Neck, C. P., \& Manz, C. C. (2012b). Effective stress management: A model of emotional intelligence, self-leadership, and student stress coping. Journal of Management Education, 36, 220-238. https://doi.org/10.1177/1052562911430205.

Ilgen, D. R., \& Pulakos, E. D. (1999). The changing nature of performance: Implications for staffing, motivation, and development. San Francisco, CA: Jossey-Bass 
Jebb, A. T., \& Tay, L. (2017). Introduction to time series analysis for organizational research: Methods for longitudinal analyses. Organizational Research Methods, 20, 61-94. https://doi.org/10.1177 $/ 1094428116668035$.

Jongerling, J., Laurenceau, J.-P., \& Hamaker, E. L. (2015). A multilevel (1) model: Allowing for interindividual differences in trait-scores, inertia, and innovation variance. Multivariate Behavioral Research, 50, 334-349. https://doi.org/10.1080/00273171.2014.1003772.

Killen, A., \& Macaskill, A. (2015). Using a gratitude intervention to enhance well-being in older adults. Journal of Happiness Studies, 16, 947-964. https://doi.org/10.1007/s10902-014-9542-3.

Konradt, U., Andreßen, P., \& Ellwart, T. (2009). Self-leadership in organizational teams: A multilevel analysis of moderators and mediators. European Journal of Work and Organizational Psychology, 18, 322-346. https://doi.org/10.1080/13594320701693225.

Krentzman, A. R., Mannella, K. A., Hassett, A. L., Barnett, N. P., Cranford, J. A., Brower, K. J., Higgins, M. M., \& Meyer, P. S. (2015). Feasibility, acceptability, and impact of a web-based gratitude exercise among individuals in outpatient treatment for alcohol use disorder. The Journal of Positive Psychology, 10, 477488. https://doi.org/10.1080/17439760.2015.1015158.

LaPorte, R. E., \& Nath, R. (1976). Role of performance goals in prose learning. Journal of Educational Psychology, 68, 260-264. https://doi.org/10.1037//0022-0663.68.3.260.

Locke, E. A., \& Latham, G. P. (1984). Goal setting: A motivational technique that works! Englewood Cliffs, NJ: Prentice Hall. https://doi.org/10.1016/0090-2616(79)90032-9.

Locke, E. A., \& Latham, G. P. (2002). Building a practically useful theory of goal setting and task motivation: A 35-year odyssey. American Psychologist, 57, 705. https://doi.org/10.1037//0003-066x.57.9.705.

Luthans, F., Luthans, K. W., \& Luthans, B. C. (2004). Positive psychological capital: Beyond human and social capital. Business Horizons, 47, 45-50. https://doi.org/10.1016/j.bushor.2003.11.007.

Luthans, F., Avey, J. B., Avolio, B. J., \& Peterson, S. J. (2010). The development and resulting performance impact of positive psychological capital. Human Resource Development Quarterly, 21, 41-67. https://doi. org/10.1002/hrdq.20034.

Lyubomirsky, S., Sousa, L., \& Dickerhoof, R. (2006). The costs and benefits of writing, talking, and thinking about life's triumphs and defeats. Journal of Personality and Social Psychology, 90, 692-708. https://doi. org/10.1037/0022-3514.90.4.692.

MacLeod, A. K., Coates, E., \& Hetherton, J. (2008). Increasing well-being through teaching goal-setting and planning skills: Results of a brief intervention. Journal of Happiness Studies, 9, 185-196. https://doi. org/10.1007/s10902-007-9057-2.

Manz, C. C. (1986). Self-leadership: Toward an expanded theory of self-influence processes in organizations. Academy of Management Review, 11, 585-600. https://doi.org/10.5465/amr.1986.4306232.

Manz, C. C. (1992). Mastering self-leadership: Empowering yourselffor personal excellence (1st ed.). Upper Saddle River, NJ: Prentice Hall. https://doi.org/10.1016/0090-2616(92)90067-w.

Manz, C. C., \& Neck, C. P. (2004). Mastering self-leadership: Empowering yourself for personal excellence (3rd ed.). Upper Saddle River, NJ: Pearson Prentice Hall.

Manz, C. C., \& Sims, H. P., Jr. (2001). The new superleadership: Leading others to lead themselves. San Francisco, CA: Berrett-Koehler. https://doi.org/10.5465/ame.2001.5898769.

Maykrantz, S. A., \& Houghton, J. D. (2018). Self-leadership and stress among college students: Examining the moderating role of coping skills. Journal of American College Health. Advance online publication. https://doi.org/10.1080/07448481.2018.1515759.

McCabe, K., Bray, M. A., Kehle, T. J., Theodore, L. A., \& Gelbar, N. W. (2011). Promoting happiness and life satisfaction in school children. Canadian Journal of School Psychology, 26, 177-192. https://doi. org/10.1037/e622482010-001.

Mento, A. J., Steel, R. P., \& Karren, R. J. (1987). A meta-analytic study of the effects of goal setting on task performance: 1966-1984. Organizational Behavior and Human Decision Processes, 36, 52-83. https://doi.org/10.1016/0749-5978(87)90045-8.

Meyers, C., van Woerkom, M., \& Bakker, A. B. (2013). The added value of the positive: A literature review of positive psychology interventions in organizations. European Journal of Work and Organizational Psychology, 22, 618-632. https://doi.org/10.1080/1359432x.2012.694689.

Miller, R. B., Behrens, J. T., Greene, B. A., \& Newman, D. (1993). Goals and perceived ability: Impact on student valuing, self-regulation, and persistence. Contemporary Educational Psychology, 18, 2-14. https://oi.org/10.1006/ceps.1993.1002.

Molenaar, P. C. (2004). A manifesto on psychology as idiographic science: Bringing the person back into scientific psychology, this time forever. Measurement, 2, 201-218. https://doi.org/10.1207/s15366359 mea0204_1. 
Mongrain, M., \& Anselmo-Matthews, T. (2012). Do positive psychology exercises work? A replication of Seligman et al. (2005). Journal of Clinical Psychology, 68, 382-389. https://doi.org/10.1002/jclp.21839.

Morin, L., \& Latham, G. (2000). The effect of mental practice and goal setting as a transfer of training intervention on supervisors' self-efficacy and communication skills: An exploratory study. Applied Psychology, 49, 566-578. https://doi.org/10.1111/1464-0597.00032.

Murphy, S. E., \& Ensher, E. A. (2001). The role of mentoring support and self-management strategies on reported career outcomes. Journal of Career Development, 27, 229-246. https://doi.org/10.1177 /089484530102700401.

Neck, C. P. (1996). Thought self-leadership: A self-regulatory approach towards overcoming resistance to change. International Journal of Organizational Analysis, 4, 202-216. https://doi.org/10.1108/eb028849.

Neck, C. P., \& Houghton, J. D. (2006). Two decades of self-leadership theory and research - Past developments, present trends, and future possibilities. Journal of Managerial Psychology, 21, 270-295. https://doi.org/10.1108/02683940610663097.

Neck, C. P., \& Manz, C. C. (1992). Thought self-leadership: The impact of self-talk and mental imagery on performance. Journal of Organizational Performance, 12, 681-699. https://doi.org/10.1002 /job.4030130705.

Neck, C. P., \& Manz, C. C. (1996). Thought self-leadership: The impact of mental strategies training on employee cognition, behavior, and affect. Journal of Organizational Behavior, 17, 445-467. https://doi. org/10.1002/(SICI)1099-1379(199609)17:5.

Neck, C. P., Nouri, H., \& Godwin, J. L. (2004). How self-leadership affects the goal-setting process. Human Resource Management Review, 13, 691-707. https://doi.org/10.1016/j.hrmr.2003.11.009.

Pietrowsky, R., \& Mikutta, J. (2012). Effects of positive psychology interventions in depressive patients - A randomized control study. Psychology, 3, 1067-1073. https://doi.org/10.4236/psych.2012.312158.

Proyer, R. T., Gander, F., Wellenzohn, S., \& Ruch, W. (2014). Positive psychology interventions in people aged 50-79 years: Long-term effects of placebo-controlled online interventions on well-being and depression. Aging \& Mental Health, 18, 997-1005. https://doi.org/10.1080/13607863.2014.899978.

Prussia, G. E., Anderson, J. S., \& Manz, C. C. (1998). Self-leadership and performance outcomes: The mediating influence of self-efficacy. Journal of Organizational Behavior, 19, 523-538. https://doi. org/10.1002/(sici)1099-1379(199809)19:5.

Raabe, B., Frese, M., \& Beehr, T. A. (2007). Action regulation theory and career self-management. Journal of Vocational Behavior, 70, 297-311. https://doi.org/10.1016/j.jvb.2006.10.005.

Ryan, T. A. (1970). Intentional behavior. New York, NY: Ronald Press. https://doi.org/10.1177 /0002764270014001111.

Sampl, J., Maran, T., \& Furtner, M. R. (2017). A randomized controlled pilot intervention study of a mindfulness-based self-leadership training (MBSLT) on stress and performance. Mindfulness, 8, 13931407. https://doi.org/10.1007/s12671-017-0715-0.

Scheines, R., Hoijtink, H., \& Boomsma, A. (1999). Bayesian estimation and testing of structural equation models. Psychometrika, 64, 37-52.

Schmid, C., \& Duan, N. (2014). The decide methods center n-of-1 guidance panel. In R. L. Kravitz \& N. Duan (Eds.), Design and implementation of $N$-of-1 trials: A user's guide (pp. 33-53). Rockville, MD: Agency for Healthcare Research and Quality Retrieved from www.effectivehealthcare.ahrq.gov/N-1-Trials.cfm.

Seear, K. H., \& Vella-Brodrick, D. A. (2013). Efficacy of positive psychology interventions to increase wellbeing: Examining the role of dispositional mindfulness. Social Indicators Research, 114, 1125-1141. https://doi.org/10.1007/s11205-012-0193-7.

Seijts, G. H., \& Latham, G. P. (2005). Learning versus performance goals: When should each be used? The Academy of Management Executive, 19, 124-131. https://doi.org/10.5465/ame.2005.15841964.

Seligman, M. E. P., \& Csikszentmihalyi, M. (2000). Special issue on happiness, excellence, and optimal human functioning. American Psychologist, 55, 5-183. https://doi.org/10.1037/0003-066X.60.5.410.

Seligman, M. E. P., Steen, T. A., Park, N., \& Peterson, C. (2005). Positive psychology progress: Empirical validation of interventions. American Psychologist, 60, 410-421. https://doi.org/10.1037/0003-066 x.60.5.410.

Sin, N. L., \& Lyubomirsky, S. (2009). Enhancing well-being and alleviating depressive symptoms with positive psychology interventions: A practice-friendly meta-analysis. Journal of Clinical Psychology, 6, 467-487. https://doi.org/10.1002/jclp.20593.

Sitzmann, T., \& Ely, K. (2011). A meta-analysis of self-regulated learning in work-related training and educational attainment: What we know and where we need to go. Psychological Bulletin, 137(3), 421442 https://doi.org/10.1037/a0022777. 
Spiegelhalter, D. J., Best, N. G., Carlin, B. P., \& van der Linde, A. (2002). Bayesian measures of complexity and fit. Journal of the Royal Statistical Society, Series B, 64, 583-639. https://doi.org/10.1111/14679868.00353.

Stewart, G., Carson, K., \& Cardy, R. (1996). The joint effects of conscientiousness and self-leadership training on employee self-directed behavior in a service setting. Personnel Psychology, 49, 143-164. https://doi. org/10.1111/j.1744-6570.1996.tb01795.x.

Stewart, G., Courtright, S. H., \& Manz, C. C. (2011). Self-leadership: A multilevel review. Journal of Management, 37, 185-222. https://doi.org/10.1177/0149206310383911.

Sweetman, D., Luthans, F., Avey, J. B., \& Luthans, B. C. (2011). Relationship between positive psychological capital and creative performance. Canadian Journal of Administrative Sciences, 28, 4-13. https://doi. org/10.1002/cjas. 175 .

Unsworth, K. L., \& Mason, C. M. (2012). Help yourself: The mechanisms through which a self-leadership intervention influences strain. Journal of Occupational Health Psychology, 17, 235-245. https://doi. org/10.1037/a0026857.

Wheeler, A. R., Shanine, K. K., Leon, M. R., \& Whitman, M. V. (2014). Student-recruited samples in organizational research: A review, analysis, and guidelines for future research. Journal of Occupational and Organizational Psychology, 87, 1-26. https://doi.org/10.1111/joop.12042.

Wood, R., \& Locke, E. (1990). Goal setting and strategy effects on complex tasks. In B. Staw \& L. Cummings (Eds.), Research in organizational behavior. Greenwich, CT: JAI Press.

Woodworth, R. J., O’Brien-Malone, A., Diamond, M. R., \& Schüz, B. (2016). Happy days: Positive psychology interventions effects on affect in an n-of-1 trial. International Journal of Clinical and Health Psychology, 16, 21-29. https://doi.org/10.1016/j.ijchp.2015.07.006.

Publisher's Note Springer Nature remains neutral with regard to jurisdictional claims in published maps and institutional affiliations. 